\title{
LAS ORGANIZACIONES, EL PODER Y MICHEL FOUCAULT
}

IORGANIZATIONS, POWER AND MICHEL FOUCAULT

\author{
Javier Carreón Guillén \\ Guillermo Campos y Covarrubias \\ Escuela Nacional de Trabajo Social \\ Universidad Nacional Autónoma de México. México/Mexico \\ javierg@servidor.unam.mx \\ omg@correo.unam.mx
}

Recibido/Received: 07/05/08

Aceptado/Accepted: 21/07/08

\section{RESUMEN}

Max Weber establece que en las organizaciones coexisten el poder y la dominación; entendiendo el poder como la capacidad de disponer de ciertos recursos (económicos, la fuerza, el conocimiento, etcétera). Ahora bien, al operar en una organización -utilizando los recursos; esto es, el poder- y requerir que las órdenes sean obedecidas, es menester aplicar la dominación, ello mediante la racionalidad del cuadro administrativo. Este juicio le atribuye a la administración, como es de suponer, un papel muy reaccionario; sin embargo, Foucault mediante la microfísica del poder, vuelve a replantear el problema, relevando a la administración de cualquier sospecha de conservadurismo.

\section{PALABRAS CLAVE:}

Dominación, poder, epistemología, cuadro administrativo, control.

\begin{abstract}
Max Weber alleged that power and domination coexist in organizations; and that power is the ability to attain certain resources (economic, force, knowledge, etc.). When an organization is operating -using these resources, e.g., power-, and requires that orders are observed, domination must be applied under the logic of the administrative framework. This assumption attributes, as expected, a very reactionary role to the administration. Foucault rephrases the dilemma using the microphysics of power, relieving the administration of any suspicion of conservatism.
\end{abstract}

\section{KEYWORDS}

Domination, power, epistemology, administrative framework, control. 


\section{LAS ORGANIZACIONES, EL PODER Y MICHEL FOUCAULT ${ }^{1}$ EL JUSTIFICABLE PRETEXTO EPISTEMOLÓGICO}

Para los propósitos que tenemos pensado encarar en el presente trabajo, requerimos de manera inicial de un singular pretexto: un breve pero efectivo auxilio de la epistemología. En ese sentido, al asumir la tarea de conceptuar lo que es y trata la epistemología, corremos el ineludible riesgo de caer en la trampa del reduccionismo, y al mismo tiempo, contrariar la sabia posición de Jean Piaget (Piaget, 1985:14), el cual esgrime la idea de que la epistemología, de ninguna manera, puede ser explicada con base en definiciones apriorísticas; sin embargo, pese a estas circunstancias, de manera opuesta a lo recomendado, podríamos establecer que "la epistemología es una disciplina que se ocupa de estudiar los conocimientos en función de su construcción real; esto es, de sus supuestos, de sus leyes y formas de operación".

Consecuente con el párrafo anterior, sabemos que la epistemología contempla en su análisis un "sujeto" y un "objeto" en la construcción de un determinado conocimiento. Ahora bien, si nuestro conocimiento resultara ser la administración, ¿cuál sería la perspectiva epistémica, el "sujeto" y el "objeto" de estudio? Al responder a este interrogante, decir que incluso todavía hoy -desde los escasos enfoques teóricos conocidos en nuestros países subdesarrollados y dependientes- sabemos poco del "sujeto" (los administradores) y todavía menos del "objeto" (las organizaciones). Por razones temáticas, en esta oportunidad, dejaremos de lado de manera intencional, de la dicotomía epistémica descrita, al "sujeto". En tal virtud, sólo nos constreñiremos, para el logro de nuestros objetivos particulares, al "objeto" de estudio; es decir, a las organizaciones.

El escudriñar a las organizaciones desde la perspectiva epistemológica, resulta un ejercicio apasionante. Sí miramos con un poco de detenimiento, para fines prácticos en estos momentos de apertura del siglo XXI, nada ni nadie escapa al influjo de las organizaciones, llámense estas empresas, instituciones, asociaciones, etcétera. Por ejemplo, hoy en día, ¿qué ciudadano medio del mundo puede vivir sin la influencia -directa o indirecta- de las organizaciones? Nos podemos incluso preguntar y también contestar: ¿Son imprescindibles para los ciudadanos mexicanos, del medio urbano, algunas de las siguientes organizaciones y empresas: la Organización de las Naciones Unidas, el Fondo Monetario Internacional, el Banco Mundial, la Federación Internacional de Fútbol Asociación. La Iglesia Católica, Apostólica y Romana, la Organización de Países Exportadores de Petróleo, Amnistía Internacional, la NASA, Microsoft, Ford, Producciones Walt Disney, Nokia, Gillette, Greenpeace, General Motors, Telefónica, Xerox, Sony, Nestlé, Volkswagen, Revlon, Coca Cola, Canon, Wal Mart, Endesa, Bayer, Colgate-Palmolive, Adidas, McDonald's, Boeing, Kodak, Procter \& Gamble, Siemens, Du Pont, Televisa, Teléfonos de México, Banco Santander, Aeroméxico, Condumex, la Comisión Federal de Electricidad, Petróleos Mexicanos, el Instituto 
Mexicano del Seguro Social, la Panificación Bimbo, el Partido Revolucionario Institucional, el Banco Nacional de México, la Confederación de Trabajadores de México, Mexicana de Aviación, el Banco Bilbao Vizcaya Argentaria-Bancomer, el Partido de la Revolución Democrática, Cementos Mexicanos, el Sistema de Trasporte Colectivo Metro, el Partido Acción Nacional, el Instituto Federal Electoral, el Instituto Politécnico Nacional, la Universidad Nacional Autónoma de México? La respuesta es, desde luego, obvia. No requiere mayores explicaciones. Siendo apenas un puñado de organizaciones, su repercusión en nuestras vidas cotidianas es manifiesta ${ }^{2}$. Esta es la dimensión y trascendencia de las organizaciones, de ahí la importancia de estudiarlas desde sus múltiples aristas.

Desde otro ángulo muy diferente, pero teniendo presente a las organizaciones, apreciamos que las preguntas y las inquietudes surgen por doquier: ¿qué son las organizaciones?, ¿cuál es el ciclo de vida de las organizaciones?, ¿por qué organizaciones como la Iglesia Católica y el ejército han perdurado por siglos?, ¿por qué convivimos en un mundo lleno de organizaciones?, ¿por qué nos organizamos como nos organizamos y no de otra manera?, ¿son las organizaciones un mal necesario?, ¿por qué a pesar de lo que se diga y juzgue, las organizaciones no le han podido proporcionar al hombre la felicidad esperada?, ¿por qué según todos los indicios, las organizaciones prohíjan el éxito de pocos y la pobreza de muchos?, ¿cuáles son las similitudes y diferencias entre empresas y organizaciones? ¿son como se afirma, las organizaciones más poderosas que los propios gobiernos?, ¿por qué tenemos la clara impresión de que el llamado éxito, arropado por las organizaciones, siempre suma cero; es decir, lo que uno gana los demás, por desgracia, lo pierden?, ¿no podrá, en el seno de las organizaciones, darse un éxito social; esto es, humano, en que todos ganemos, al menos un poco?, ¿cuál es la posición del positivismo y el neopositivismo frente a las organizaciones?, ¿de qué manera encara la hermenéutica a las organizaciones?, ¿en qué se distingue la dialéctica de su enfoque hacía las organizaciones?, ¿qué papel juega la teoría crítica en su relación con las organizaciones?, ¿son las organizaciones un medio o un fin?, etcétera.

Como puede observarse hemos preferido quedarnos, en nuestro intento por aproximarnos a las organizaciones, en las interrogantes, las inquietudes y los planteamientos de la problemática epistémica (gérmenes de presentes y futuras líneas de investigación), para no caer en la manida situación de que: "nuestra sociedad es -como ya es bien sabido- una sociedad con preeminencia organizacional; ya que por lo general, nacemos dentro de una organización (hospital), consumimos una buena parte de nuestra existencia preparándonos en organizaciones (escuelas), nos ganamos la vida en organizaciones (trabajo), proveemos nuestros distintos bienes y servicios de organizaciones (mercados, tiendas, comercios, etcétera), nos distraemos, divertimos y practicamos la recreación en organizaciones (cines, teatros, deportivos, espectáculos, etcétera) y 
concluimos, en términos generales, nuestra existencia en una organización (panteón)". Todo ello sin considerar a la familia que también es una organización.

\section{2. ¿SON LAS ORGANIZACIONES ENTES SOCIALES ASÉPTICOS?}

Es evidente que pese a las limitaciones existentes ${ }^{3}$, la teoría de la organización exhibe una inusitada preocupación por incursionar en el pensamiento político, incluyendo desde luego, los ámbitos de la empresa misma ${ }^{4}$, incorporando temas tan controvertidos como: el poder y la dominación, el liderazgo, los conflictos, la especialización flexible, el regulacionismo, el corporativismo, el proceso de trabajo y la democratización, entre otros.

Por definición, el orden en la organización es siempre inestable. Las tensiones, los conflictos, la incertidumbre, la ambigüedad, las desigualdades, las contradicciones de orígenes exógenos y endógenos se encargar de alimentar el movimiento (Chanlat, 1994:346). En suma, lo que priva en el seno de las organizaciones es la lucha entre diversas y complejas fuerzas soterradas o abiertas, las cuales resultan generalmente asimétricas. No obstante esta concepción, subsisten otras en clara oposición que, de manera simple y hasta vulgar, argumentan que, por ejemplo, desde la óptica del pensamiento funcionalista -tan arraigado en el ámbito del estudio de las organizaciones-: sólo es problema lo que puede ser resuelto. Desde luego, este planteamiento es insostenible, ya que las estructuras y los conflictos en las organizaciones son de carácter histórico y no es posible reconocer a priori límites en sus posibilidades de cambio y transformación (Ballina, 2001:64). Por si lo anterior no resultara convincente, podemos también observar como actualmente, ciertas corrientes positivistas y neopositivistas, están empecinadas en de plano trivializar la teoría de la organización; por lo que conciben que al interior de las propias organizaciones todo es posible: la complejidad no existe, las recetas son desde luego factibles y lógicas (de esta suerte arribamos a la prescripción en todo su apogeo; con autores tan paradigmáticos para el caso como Mario Borghino y su inefable texto: Los 7 hábitos de la gente altamente efectiva de Stephen R. Covey, México, Paidós, 2002) El voluntarismo por su parte anula las paradojas, por lo que todo lector de este tipo de textos puede ser convertido, prácticamente de la noche a la mañana, en un genuino gerente de excelencia ${ }^{5}$, todo ello en unas cuantas lecciones (recuérdese a Miguel Ángel Cornejo y su excelencia light). Es este un mundo, en donde la verdad es obvia, en donde tampoco existe espacio, ni el tiempo, ni mucho menos el interés para las cuestiones epistemológicas, ipara qué, sí lo importante es disponer de una administración con fines que privilegien lo crematístico! En fin, en donde, finalmente, la fantasía y la magia envuelven y subyugan, movilizando emociones, como seguramente jamás la administración lo había logrado (Mayoral, 1999:50).

Huelga decir que bajo el paradigma positivista en su vinculación con las organizaciones; "todo parece desenvolverse sin mácula, sin mancha alguna, las 
contradicciones simplemente no existen, son una fantasía". Da la impresión que hemos arribado al mejor de los mundos posibles; es decir, al famoso Mundo feliz de Aldous Huxley o bien a la ya lejana y famosa Utopía de Tomás Moro. Lo cierto es que, según nuestro particular punto de vista, las organizaciones no pueden ser por ningún motivo, como se pretende, asépticas. La dialéctica; es decir, la contradicción es lo que campea en ellas. Empero, en este caso, lo más importante es resolver la incógnita: ¿por qué las organizaciones tienden a albergar, de forma notoria y evidente, la contradicción en su interior?

\section{EL PODER Y LA DOMINACIÓN}

Para continuar con nuestro trabajo pongamos en claro que los entes sociales llamados organizaciones requieren ser administrados; sin embargo, resulta muy pertinente el preguntarnos ¿por qué? La respuesta con apariencia de muy evidente, de ninguna manera resulta sencilla. Al tratar de contestarla tendremos necesariamente que complejizar, de alguna manera, la situación hasta ahora esgrimida; es decir, superar los tradicionales paradigmas positivistas. Tal sería el caso sí, por ejemplo, recurrimos al famoso pensador alemán Max Weber, quien en su obra póstuma: Economía y sociedad, nos plantea que al interior de las organizaciones se ejerce a plenitud tanto el poder ${ }^{6}$ como la dominación ${ }^{7}$. Weber orienta la dominación como una evidente relación social, pero no limita su análisis a la interacción entre sólo un individuo que manda y otro que obedece. No. Aquí lo importante es destacar que cuando, en una organización, se ejerce de manera racional la dominación -previa instauración y ejercicio del poder- sobre un núcleo más o menos amplio de individuos, es menester el disponer de un determinado cuadro administrativo. Tal y como se ve, la pregunta -planteada en los tres primeros renglones del presente parágrafo- nos la ha respondido Max Weber con toda claridad, reiterando la indispensable presencia del cuadro administrativo en el espacio que ocupan las organizaciones.

Ante tan peculiar situación, lo menos que podemos decir es que no nos agrada, para nada, el hecho de que sea el cuadro administrativo, el que supuestamente coadyuve -en el campo de las organizaciones- de forma determinante al ejercicio racional de la dominación. Tal parece que el rol que se le asigna a la administración resulta, los menos que se podría decir, reaccionario. Sobre el particular, los diversos juicios y puntos de vista se pueden calificar de controvertidos y apasionados. Pese a ello, habrá que decirlo sin ambages, los estudios tanto teóricos como empíricos al respecto, son bastante escasos, salvo los weberianos y más recientemente los propuestos por Michel Foucault. Por ello es nuestro propósito el rescatar -en alguna medida- en las siguientes páginas, al controvertido filósofo francés, a fin intentar desmitificar, en lo antes apuntado, tanto a la administración como al poder mismo, dejando claro el papel que al respecto juegan las organizaciones. 


\section{MICHEL FOUCAULT, EL PODER Y LA DOMINACIÓN}

¿Por qué proponemos lo anterior? Porque de manera simple y concreta bajo la égida del pensamiento de corte marxista-economicista, hemos vivido una especie de secuestro de los conceptos: poder y dominación, así como de su propia acción. En efecto, para Michel Foucault el conocimiento y el poder se encuentran interpenetrados y su cohesión gravita con una presencia destacada en todas las sociedades con un cierto nivel de industrialización, impregnándolas hasta en los más íntimos pliegues de su vida cotidiana. Según nuestro autor, la forma de dominación característica y prevaleciente del capitalismo histórico no es pues, como se piensa de manera errónea, la explotación, ni la alienación, ni la represión, ni la anomia, ni mucho menos la conducta disfuncional. Para él la nueva pauta de control social es aquella que se encuentra larvada en distintos y numerosos puntos del terreno social, formando una especie de constelación de estructuras, la cual está en todas partes y en ninguna a la vez; nos referimos, claro está, a lo que Foucault denomina como la microfísica del poder (Poster, 1991:113-4), la cual como veremos, se convierte en uno de los sustentos teóricos de nuestro autor.

A fin de profundizar un poco más en los preceptos marxistas, recurramos ahora para analizar el poder, al concepto de proceso de trabajo ${ }^{8}$ que el propio Marx lo teoriza no haciendo del todo comprensibles algunos elementos de las posiciones radicalizadas, las cuales, por cierto, son las adecuadas para derribar los actuales modos de dominación. Empero, lo importante no es que el proceso de trabajo esté o no libre de determinadas opresiones o de las "tecnologías del poder" predominantes, sino al hecho de que al pasar a los nuevos conceptos críticos se cumple mejor mediante la referencia a otras prácticas sociales. La verdad es que, esto a su vez, vino dependiendo, por una parte, de que el marxismo impunemente haya colonizado la categoría del trabajo; y por la otra parte, de que las estructuras dominantes se han estado desarrollando en otros espacios muy diferentes a los señalados por el marxismo; por ejemplo: en las prácticas del castigo y de la sexualidad $^{9}$, en las múltiples circunstancias y espacios propios de la familia, en las fuerzas armadas y en los asilos. Foucault ha sacado también a la luz el nacimiento y desarrollo de nuevas maneras de dominación; en las cuales se dan singulares combinaciones de discursos [el cual por cierto no es para él una representación idealista, sino más bien concibiéndolo al modo materialista, es parte de la estructura del poder de la sociedad] y prácticas que constituyen nuevas formas de subyugación. Desde luego todo este proceso afectó también las complejas relaciones laborales que se dan bajo el sistema capitalista -en el seno mismo de las organizaciones- pero no de la manera como lo concebía Marx. Por lo mismo, la disciplina laboral impuesta a los trabajadores en la fábrica -tal y como lo asevera Foucault y revisaremos más adelante- no tiene porque ser equiparada con los mecanismos de explotación ${ }^{10}$ y alienación ${ }^{11}$ hasta hoy planteados de manera enfática por el marxismo (Poster, 1991:115-6). 
Con el ánimo de ir clarificando un poco el pensamiento foucaultiano relativo al poder, pero sobre todo enfocándolo a uno de sus brazos más importantes: el control. Describimos a continuación, de manera apretada, la forma cómo emergió la moderna educación (de la que hoy en día todo mundo habla), y de la que Foucault nos da buena cuenta, según su peculiar y aguda forma de analizar las cosas. La aparición de la educación en su sentido moderno estuvo vinculada con cambios importantes que estaban teniendo lugar en el siglo XIX. Uno de ellos era el desarrollo de los colegios. Se podría incluso pensar de forma un tanto cuanto ingenua que existía una demanda (lugares en las aulas) de educación -como ocurre actualmente- y que los colegios y universidades se fundaron bajo la lógica de darle cabal respuesta mediante una determinada oferta (aulas, pupitres, maestros, materiales didácticos, etcétera.) Pero las cosas no ocurrieron así. Los colegios surgieron, como bien lo ha demostrado el propio Michel Foucault, como parte del aparato administrativo del Estado moderno. En otras palabras, el "plan de estudios oculto" el cual tenía que ver con la disciplina y el control de los niños y jóvenes, (Giddens, 1999:544) ¡Ni más, ni menos!

\section{HACIA UNA TEORÍA FOUCAULTIANA DEL PODER}

De toda la amplia y compleja "Visión Genealógica" desarrollada por Foucault nos proponemos, para interpretar su concepción teórica, en cuanto es de nuestro interés, el dirigir nuestro enfoque, por principio de cuentas, al análisis que se ubica en el ejercicio del poder y su tradicional vinculación marxista con la economía. Sobre el particular, todo lo plantea el pensador francés en tres diferentes preguntas: 1) ¿Está siempre el poder en posición secundaria respecto a la economía? 2) ¿Tiene el poder esencialmente como razón de ser y como fin servir a la economía? 3) ¿Está destinado a hacerla funcionar, a solidificar, mantener, reproducir, las relaciones propias de dicha economía y esenciales para su funcionamiento? (Foucault, 1980:134).

La respuesta a estas interrogantes estaría en precisar qué es realmente el poder desde su ejercicio mismo. Foucault no encuentra otra alternativa que decirnos que el poder es en esencia lo que reprime. En suma, el poder reprime a la naturaleza, los instintos, a una clase social determinada, a los individuos. Pues bien, sí el poder es en realidad el despliegue de una relación de fuerzas, más que hacerlo -como indebidamente se hace- bajo preceptos de cesión, contrato, alienación, o, en términos funcionales del mantenimiento de las relaciones de producción; por lo mismo: ¿no debería ser analizado en términos de lucha, de enfrentamientos, de guerra? Con esta resolución estaríamos creando una nueva hipótesis, paralela en importancia a la que establece que la mecánica del poder es esencialmente represión. Por lo mismo, bien podría formularse una nueva hipótesis, la cual nos dice que el poder es la lucha continuada, la guerra con otros medios, (Foucault, 1980:135). Posición opuesta al juicio del historiador suizo Jacobo Burckhardt 
[1818-1897], quien acuñara la famosa frase de que la: "guerra es la política con otras armas".

Tenemos así que el poder se expresa en todos los espacios posibles como represión pero es también guerra, lucha abierta o soterrada, entre actores, generalmente asimétricos. El poder se define, pues, como una prolongación "pacífica" de la guerra o como guerra silenciosa o de baja intensidad. Una lucha llena de sutilezas, cuya misión básica es la de fortalecer y recrear las fuerzas desiguales en todos los ámbitos de la sociedad, incluyendo, claro está, a las organizaciones, (Ceballos, 1994:34).

Para darle término a nuestro sintético análisis encuadrado en el capitalismo histórico, tratemos enseguida el llamado poder disciplinario. La implantación de la disciplina capitalista, al interior de las organizaciones y en particular de las empresas, implica una aceptación -tácita o implícita- por parte de los dominados de toda una compacta y singular caterva de obligaciones, compromisos y responsabilidades laborales ${ }^{12}$. La disciplina laboral surge entonces como esa necesidad históricamente específica de garantizar la producción capitalista en constante ascenso. No es casual que la sutil disciplina -en específico la laboral, y de manera general la que se asume en todo el sistema capitalista- contribuya, de manera decisiva, a lo que los economistas definen como nuevas formas de acumulación; es decir, lo que los administradores denominamos -en el seno de las organizaciones- como nuevas formas de organización del trabajo (penetradas por la microfísica del poder y asumiendo una -nueva y muy peculiar- disciplina laboral). En tal virtud, no nos debe extrañar que la disciplina capitalista en su conjunto sea una forma de acumular hombres y mujeres que dispongan de una nueva mentalidad reglamentada y normativizada que los convierta en eficaces y productivos trabajadores. Pero tampoco lo podemos soslayar en: cumplidores contribuyentes de sus obligaciones fiscales, en pasivos espectadores de las políticas neoliberales, en incondicionales adeptos de la $\mathrm{TV}^{13}$, y omisos lectores de periódicos y revistas, en mudos testigos de la grave y creciente violencia intrafamiliar; en fin, en ciudadanos insensibles ante cerca de trescientos impunes asesinatos, de indefensas mujeres, en la población fronteriza con los Estados Unidos, Ciudad Juárez, Chihuahua, etcétera., sustituyendo con todo ello, de manera muy cómoda y efectista los antiguos y costosos procedimientos de control, (Ceballos, 1994:69). Para eso y mucho más sirve la disciplina en el sistema capitalista.

En conclusión, tenemos que la microfísica del poder, constituida por una vasta tecnología que de manera práctica y sutil atraviesa todo el conjunto de las relaciones sociales, está presente en muchísimos más actos sociales de los que nos podemos imaginar. Estamos pues, según la teoría foucaultiana, ante una maquinaria que produce efectos de dominación de un cierto tipo muy peculiar de estrategias y tácticas específicas. Ante todo esto, para nosotros -como administradores y estudiosos de las organizaciones- es muy importante el replantearnos el rol que supuestamente algunos le atribuyen al cuadro administrativo (el de cómplice del 
poder), bajo la racionalidad del sistema capitalista. Como lo podemos apreciar fehacientemente, en el planteamiento que formula Foucault, establece que el poder exhibe mucho más atributos y características que las que generalmente le venimos atribuyendo.

Es también menester, desde los enfoques marxistas, el volver a replantear cuantas veces sea necesario- la importancia de lo económico frente al poder. No podemos por lo mismo permitir que esta especie de estalinismo ${ }^{14}$, el cual dogmáticamente secuestra y se apropia ad infinitum de las ideas, de los conceptos y hasta de los hechos mismos, continúe prevaleciendo en el pensamiento marxista. Por todo ello, al darle un peso específico sobrevaluado a lo económico, estamos como de hecho nos quiere decir Michel Foucault- castrando otras legítimas y reales manifestaciones de la microfísica del poder, "llevándose entre las patas", en una buena medida, al cuadro administrativo en su actuar -como uno de los supuestos brazos de la dominación- en las organizaciones. Por todo ello, lo reiteramos: no menos importantes deben resultar los todavía parcialmente explorados estudios weberianos sobre administración; los cuales es necesario, para la teoría de la administración y de la organización, el replantearlos e incluso -¿por qué no?superarlos. La posibilidad aunque remota existe. Los enfoques teóricos son hoy más que nunca, para nuestros países, insoslayables.

Es lógico pensar y suponer que, por su parte, desde la óptica foucaultiana se abren, para la teoría de la organización y de la administración, nuevos y promisorios horizontes para esta nueva y vigorosa profesión de carácter social: la administración; la cual pretende, a fin de cuentas, ganarse como disciplina de carácter social, el lugar que bien merece...

\section{NOTAS}

1 Pensador francés [1926-1984] considerado como un postestructuralista. Se relacionan sus ideas con las de Derrida y Lacan. Si bien existen buenas razones para ubicar a Michel Foucault en el contexto postestructuralista, se puede argumentar convincentemente también a favor de otro enfoque, el que considera a Foucault como una continuación y, a la vez, un separado de la tradición marxista. Cfr: Mark Poster. Foucault, el marxismo y la historia, Modo de producción versus modo de información, México, Paidós, 1991, p.13.

2 Para cada país en particular, las organizaciones serían bastante parecidas. Lo que finalmente nos debe quedar claro es que, querámoslo o no, vivimos, para bien o para mal, un mundo de organizaciones.

3 Nos referimos claro está a las que se viven en países como México, en donde a pesar de la escasez de recursos o precisamente debido a ello, se privilegia todo, menos los temas alusivos a la teoría.

$4 \quad \mathrm{Al}$ respecto véanse sobre todo los siguientes autores latinoamericanos: Bernardo Kliksberg, $E l$ pensamiento organizativo: del taylorismo a la teoría de la organización, Buenos Aires, Paidós, 1985; Eduardo Ibarra Colado y Luis Montaño Hirose, Mito y poder en las organizaciones, México, Trillas, 1992; Francisco Ballina Ríos, Teoría de la administración. Un enfoque alternativo, México, McGraw-Hill, 2001; Carlos Dávila Ladrón de Guevara, Teorías organizacionales y administración, Bogotá, McGraw-Hill, 1997; Eduardo Ibarra Colado y Luis Montaño Hirose (coord.), Ensayos críticos para el estudio de las organizaciones en México, México, Universidad Autónoma Metropolitana, Editorial Miguel Ángel Porrúa, 1991. 
5 Cómo es posible — se puede interrogar cualquiera de nosotros- que, por ejemplo, en el famoso libro publicado en 1982: En Busca de la Excelencia de Tom Peters y Robert Waterman (supuestamente prestigiosos consultores de empresas, uno de los cuales era profesor de la Escuela Empresarial de Stanford cuando escribió el libro), del cual se vendieron — sin exageración alguna - varios millones de ejemplares y fue producto, según sus propios autores, de más de veinte años de investigación; ponga al descubierto la deleznable situación que fue privando para ciertas organizaciones que supuestamente tenían el carácter de excelentes. Veamos: "En octubre de 1987, Business Week publicó un estudio seleccionando las $<46$ en cabeza $>$ entre las $<$ peores y más mediocres $>$. Entre esas cuarenta y seis empresas, siete estaban en la lista de las treinta y seis aplaudidas en la obra: En Busca de la Excelencia. Pocos meses más tarde, Fortune publicó su estudio anual sobre las compañías más admiradas de América. Entre las diez de cabeza, seis ni siquiera estaban en la lista de En Busca de la Excelencia. La favorita de este libro, la IBM, había descendido al puesto número treinta y dos (actualmente ronda el lugar número 245), y Wang Labs, una empresa <excelente>, según Peters y Waterman, había pasado a la cola de las, aproximadamente, 300 compañías de Fortune; en 1988 sus beneficios habían disminuido el 97\% con relación a 1987, mientras que en 1989 registró pérdidas cercanas a los 500 millones de dólares". Cfr: Spyros G. Makridakis, Pronósticos. Estrategia y Planificación para el Siglo XXI, Madrid, Ediciones Díaz de Santos, 1993, p. 2.

6 Estableciendo algunos antecedentes sobre el término, podemos decir que la palabra poder se ha utilizado hasta la saciedad y el cansancio. En términos generales el vocablo nos remite a tres nociones diferentes e interrelacionadas, las cuales contribuyen a su clarificación: a) No existe poder sin asignación de recursos, b) Se requiere de una determinada capacidad para emplear dichos recursos; es decir, una recomendable planeación, c) Reconocer su carácter estratégico; esto es, el poder se ejerce no sólo contra la inercia, sino de manera fundamental contra la resistencia de las voluntades adversas.

7 Para Max Weber la dominación es: "la posibilidad de que una orden encuentre obediencia por parte de un grupo determinado de individuos". Cfr: Max Weber, Economía y sociedad, México, Fondo de Cultura Económica, 1997, pp. 156 y ss.

Actividad racional encaminada a la producción de valores de uso, la asimilación de las materias naturales al servicio de las necesidades humanas, la condición general del intercambio de materias entre la naturaleza y el hombre, la condición eterna de la vida humana y por tanto, independientemente de las formas y modalidades de esta vida y común a todas las formas sociales por igual. Cfr: Carlos Marx, El Capital, México, Fondo de Cultura Económica, 1973, Libro I, p. 136.

9 Referente a este tema, nada despreciable por cierto, Foucault le dedicó, -ya sobre lo que él le llamó la "Visión Genealógica" (es decir, la preocupación de nuestro autor por comprender las tácticas y estrategias que utiliza el poder. Cfr: Héctor Cevallos Garibay, Foucault y el poder, México, Ediciones Coyoacán, 1994, p. 17)- su famoso texto: Historia de la sexualidad, México, Siglo XXI, 1983, Vol. I. Asimismo, no podemos omitir la valiosa y esclarecedora tesis doctoral de Rosa María Rodríguez Magda, titulada: Foucault y la genealogía de los sexos, Barcelona, Universidad Autónoma Metropolitana, Anthropos, 1999, 349 p.

10 Resulta curioso que sobre la explotación, Pablo González Casanova la haya elevado -dentro del marxismo más ortodoxo- a rango de categoría selecta, otorgándole los máximos atributos para entender y comprender la historia del capitalismo. Cfr: Pablo González Casanova, Las categorías del desarrollo económico y la investigación en ciencias sociales, México, Dirección General de Publicaciones de la UNAM, 1970, pp. 14 y ss., si el texto anterior no resultara suficiente, también realizó un estudio que tituló: Sociología de la explotación, México, Siglo XXI, 1969, 291 p.

11 El que fuera integrante de la Escuela de Frankfurt y de alguna de las corrientes marxistas: Erich Fromm, incursiona de manera decidida y no sin tropiezos, en parcelas tan llenas de complejidad para el mundo del trabajo, bajo el capitalismo histórico, como son la alienación. En efecto, desde 
los años 60's del siglo pasado se hablaba ya de la "brutal enajenación" que el trabajo producía en los obreros; sin embargo, cuarenta años después no ve uno con claridad, en las relaciones laborales capitalistas, tal alienación y sí en cambio, una muy evidente dominación [expresada en una sutil disciplina] producto del poder. Cfr: Erich Fromm, El miedo a la libertad, México, Paidós, 1977, pp. 145 y ss.

Vemos bajo muy diferentes propuestas cómo los empleadores y sus colaboradores inmediatos se esfuerzan de muchas maneras [la teoría organizacional nos habla de motivación, relaciones humanas, clima organizacional, desarrollo organizacional, etcétera] para convencer a sus subordinados que se comprometan y responsabilicen de la mejor manera posible, con sus labores de todos los días; a fin de incrementar la productividad de las organización, dentro de un sistema que privilegia la competitividad por encima de todo.

13 Haciendo caso omiso a la muy sana recomendación del filósofo español Fernando Savater, quien enfático afirma: "La televisión, en general, debe estar muy por debajo del pensamiento y las ideas de los ciudadanos comunes y corrientes. Éstos no deben dejarse vencer por aquella".

14 A este respecto el propio Michel Foucault, después de 1968 ponía el dedo en la llaga —mucho antes de que lo hiciera el poeta Octavio Paz — al hablar abiertamente sobre el Goulag estalinista. "El Goulag —escribe Foucault— debe ser analizado en tanto que operador económico-político de un Estado Socialista. Nada de reduccionismos historicistas. El Goulag no es un residuo, o una consecuencia. Es un presente candente”. Cfr: Michel Foucault, Op. Cit, p. 165.

\section{BIBLIOGRAFÍA}

BALLINA RÍOS, F. (2000): Teoría de la administración. Un enfoque alternativo, México. McGraw-Hill. CEBALLOS GARIBAY, H. (1994): Foucault y el poder, México, Ediciones Coyoacán. CHANLAT, J. F. (1994): "Hacía una antropología de la organización”, Revista de Gestión y Política Pública, México, Centro de Investigación y Docencia Económica. III. No. 2.

COVEY STEPHEN R. (2002): Los 7 hábitos de la gente altamente efectiva, México, Paidós.

DÁVILA LADRÓN DE GUEVARA, C. (1997): Teorías organizacionales y administración, Bogotá, McGraw-Hill.

FILLINGHAM, L.A. y SUSSER. M. (1998): Michel Foucault para principiantes, Buenos Aires, Era Naciente.

FOUCAULT, M. et al. (1981): Espacios de poder, Madrid, La Piqueta.

- (1980): Microfísica del poder, Madrid, La Piqueta.

FROMM, E. (1977): El miedo a la libertad, México, Paidós.

GIDDENS, A. (1999): Sociología, Madrid, Alianza.

GONZÁLEZ CASANOVA, P. (1970): Las categorías del desarrollo económico y la investigación en ciencias sociales, México, Publicaciones de la UNAM.

-(1969): Sociología de la explotación, México, Siglo XXI.

IBARRA COLADO, E. y MONTAÑO HIROSE, L. (coord.) (1991): Ensayos críticos para el estudio de las organizaciones en México, México, Universidad Nacional Autónoma de México y Editorial Miguel Ángel Porrúa.

- (1992): Mito y poder en las organizaciones. Un análisis crítico de la teoría de la organización, México, Trillas. 
KLIKSBERG, B. (1985) :El pensamiento organizativo: del taylorismo a la teoría de la organización, Buenos Aires, Paidós.

MARKIDAKIS, S. G. (1993): Pronósticos. Estrategia y planificación para el siglo XXI, Madrid, Ediciones Díaz de Santos.

MARX, C. (1973): El Capital, México, Fondo de Cultura Económica.

MAYORAL, L. (1999): "La epistemología de la administración hacía finales del siglo", en: Momento Económico, México, Instituto de Investigaciones Económicas de la UNAM, septiembre-octubre 1999. No. 150:50-54.

PETERS, T. y WATERMAN, R. (1982): In Search of Excellence. New York. Harper\& Row.

PIAGET, J. (1985): Tratado de lógica y conocimiento científico, Buenos Aires, Paidós.

POSTER, M. (1991): Foucault, el marxismo y la historia. Modo de producción versus modo de información, México, Paidós.

RODRÍGUEZ MAGDA, R. M. (1999): Foucault y la genealogía de los sexos, Barcelona, Anthropos y Universidad Autónoma Metropolitana. .

WEBER, M. (1997): Economía y sociedad, México, Fondo de Cultura Económica.

\section{Breve currículo:}

\section{Javier Carreón Guillén}

Licenciado en Historia por la Facultad de Filosofía y Letras de la Universidad Nacional Autónoma de México (UNAM). Estudios de licenciatura en economía en la Escuela Nacional de Economía de la UNAM. Maestro en Administración del Trabajo en la Universidad Autónoma Metropolitana. Doctor en Administración por la Facultad de Contaduría y Administración de la UNAM. Actualmente es Profesor de Carrera Asociado "B" de tiempo completo en la Escuela Nacional de Trabajo Social de la UNAM. Miembro del Sistema Nacional de Investigadores, Nivel I. Autor de diversas publicaciones, entre las que destacan: La planeación de la organización del trabajo frente a la globalización. El caso de la Volkswagen 1990-2000, (2006).

\section{Guillermo Campos y Covarrubias}

Licenciado en Antropología Social egresado de la Escuela Nacional de Antropología e Historia, Licenciado en Educación Básica de la Escuela Normal Rural, Maestro en Administración Pública en el Instituto de Estudios Superiores en Administración. Maestro en Sociología en la Facultad de Ciencias Políticas y Sociales de la UNAM. Doctor en Administración Pública por el Instituto de Estudios Superiores en Administración. Miembro del Sistema Nacional de Investigadores. Nivel I. Autor de diversos títulos destacando: La Investigación y las Ciencias Sociales, Economía Pobreza y Sociedad en México, (2005). Globalización, mercado de trabajo y migración de trabajadores mexicanos a Estados Unidos, (2006). 